\title{
Uma iniciativa de educação profissional para a construção de carreira dos alunos de
}

\section{Administração}

\author{
A professional education initiative for building the career of Business Administration students \\ Una iniciativa de educación profesional para construir la carrera de los estudiantes de
}

Administración de Empresas

Recebido: 20/01/2022 | Revisado: 25/01/2022 | Aceito: 04/02/2022 | Publicado: 06/02/2022

Marcello Vinicius Doria Calvosa
ORCID: https://orcid.org/0000-0003-2724-9431
Universidade Federal Rural do Rio de Janeiro, Brasil
Grupo de Pesquisas Gestão de Carreiras e Planejamento Estratégico Pessoal, Brasil
Centro de Educação a Distância do Estado de Rio de Janeiro, Brasil
mcalvosa@ gmail.com
Andreia Cristina Resende de Almeida
ORCID: https://orcid.org/0000-0002-7276-8655
Universidade Federal Rural do Rio de Janeiro, Brasil
Grupo de Pesquisas Gestão de Carreiras e Planejamento Estratégico Pessoal, Brasil
Centro de Educação a Distância do Estado de Rio de Janeiro, Brasil
andreia.almeida.res@gmail.com
Marcos Antônio da Silva Batista
ORCID: https://orcid.org/0000-0003-4443-1753
Universidade Federal Rural do Rio de Janeiro, Brasil
Grupo de Pesquisas Gestão de Carreiras e Planejamento Estratégico Pessoal, Brasil
marcosbatista@ @frrj.br
Marcos Ferreira
ORCID: https://orcid.org/0000-0003-0465-5357
Universidade Federal Rural do Rio de Janeiro, Brasil
Grupo de Pesquisas Gestão de Carreiras e Planejamento Estratégico Pessoal, Brasil
Empresa Brasileira de Pesquisa Agropecuária, Brasil
marcosppgen@ @mail.com

\section{Resumo}

A Semana Acadêmica SIGICar - Semana Acadêmica de Integração, Gestão e Insights de Carreira é uma ação de extensão desenvolvida por professores e outros atores da UFRRJ, campus Seropédica / RJ, Brasil. A SIGICar foi proposta como um espaço de diálogo e compartilhamento de experiências entre os diversos profissionais da UFRRJ e do mercado de trabalho, pautado pela liberdade de expressão, para desenvolver o senso crítico e proporcionar uma formação responsável no aluno de Administração e, por extensão, em todos os alunos convidados do Instituto de Ciências Sociais Aplicadas - ICSA / UFRRJ. Uma survey foi respondida por 168 participantes $(n=168)$, entre alunos de Administração da instituição, entre participantes $(n=71)$ e futuros participantes $(n=97)$ do evento. A questão de pesquisa do trabalho foi: - Quais formatos, temas e ideários de carreira poderiam ser oferecidos a estudantes de IES, no curso de Administração, para que o seu envolvimento seja mais participativo e essa ação de extensão consiga promover uma contribuição na formação profissional e pessoal dos alunos? As novas edições da SIGICar deverão apresentar maior número de profissionais de mercado entre os palestrantes, novas atividades propostas com material instrucional prévio distribuído, atividades em horários vespertinos e noturnos, separados por ciclo profissional. E abordar principalmente os seguintes temas: gestão de carreiras e mercado e trabalho, liderança e processos de orientação profissional, e gestão de pessoas e de pequenas empresas.

Palavras-chave: Semana acadêmica; Educação profissional; Carreira; Extensão universitária; Orientação profissional; Ensino.

\footnotetext{
Abstract

The Academic Week SIGICar - Semana Acadêmica de Integração, Gestão e Insights de Carreira is an extension action developed by professors and other actors from UFRRJ, Seropédica / RJ, Brasil. SIGICar was proposed as a space for dialogue and sharing of experiences between the various professionals of UFRRJ and the labor market, guided by freedom of expression, to develop a critical sense and provide responsible training to the Administration student and, by extension, in all invited students of the Instituto de Ciências Sociais Aplicadas - ICSA / UFRRJ. A survey was answered by 168 participants $(n=168)$, among administration students of the institution, among participants $(n=71)$ and future participants $(n=97)$ of the event. The research question of the work was: - What
} 
formats, themes and career ideas could be offered to students' University education, in the Administration course, so that their involvement is more participatory and this extension action is able to promote a contribution in professional training and student staff? The new editions of SIGICar should present a greater number of market professionals among the speakers, new activities proposed with prior instructional material distributed, activities in the afternoon and evening, separated by professional cycle. And address mainly the following topics: careers and market and work management, leadership and career guidance processes, and people and small business management.

Keywords: Academic week; Professional education; Career; University extension; Professional orientation; Teaching.

\section{Resumen}

La Semana Académica SIGICar - Semana Acadêmica de Integração, Gestão e Insights de Carreira es una acción de extensión desarrollada por profesores y otros actores de la UFRRJ, campus Seropédica / RJ, Brasil. SIGICar fue propuesto como un espacio de diálogo e intercambio de experiencias entre los diversos profesionales de la UFRRJ y el mercado de trabajo, guiado por la libertad de expresión, para desarrollar el sentido crítico y brindar una formación responsable a los estudiantes de Administración y, por extensión, a todos los estudiantes invitados del Instituto de Ciências Sociais Aplicadas - ICSA / UFRRJ. Uma survey fue respondida por 168 participantes $(\mathrm{n}=168)$, entre estudiantes de administración de la institución, entre participantes $(n=71)$ y futuros participantes $(n=97)$ del evento. La pregunta de investigación del trabajo fue: - ¿Qué formatos, temas e ideas de carrera se pueden ofrecer a los estudiantes de las universidades, en la carrera de Administración, para que su involucramiento sea más participativo y esta acción de extensión pueda promover un aporte en la formación profesional y del personal estudiantil? Las nuevas ediciones de SIGICar deberán presentar un mayor número de profesionales del mercado entre los ponentes, nuevas actividades propuestas con material didáctico previo distribuido, actividades en horario de tarde y noche, separadas por ciclo profesional. Y abordar principalmente los siguientes temas: carreras y gestión del mercado y del trabajo, liderazgo y procesos de orientación profesional, y gestión de personas y pequeñas empresas.

Palabras clave: Semana académica; Educación professional; Carrera; Extensión universitaria; Orientación profesional; Enseñanza.

\section{Introdução}

Temas interdisciplinares são fundamentais para estabelecer o sucesso no trabalho e na vida no Século XXI, preparando os estudantes para aprimorar habilidades e competências sobre informação, empregabilidade, tecnologia e profissionalização, capacidades de gestão e liderança, permitindo o seu aprimoramento e a oferta de experiências adequadas em seu atual ou futuro ambiente de trabalho, em seu o desenvolvimento humano e profissional (Partnership for 21st Century Learning [P21], 2019; Luo, 2020; Calvosa \& Ferreira, 2021). Muitos são os desafios contemporâneos envolvendo a transferência de capacidades, de competências e de conhecimento: a compreensão dos processos que tendem a cada vez mais ser digitais; o uso de comunicação virtual, multicompartilhada e fragmentada; a disseminação e aceitação das mídias sociais; o aumento de expressividades das comunidades; e o aumento da relação remota entre as pessoas (Ötting et al., 2021; Johnson et al., 2022). A nova geração de alunos [indivíduos] busca, em uma espécie de 'programa' inconsciente de ajuda pessoal, respostas para processos de cunho social, econômico e cultural, buscando eliminar conflitos, realizar ideais, coordenar contradições, estabelecer relações, desenvolver-se, capacitar-se melhor para novos desafios e ser aprimorados, de forma diferente das gerações anteriores. Em parte porque não se espelham e nem são compreendidos completamente por teoria(s) que suporte $(\mathrm{m})$ ou represente(m) às suas aspirações como geração laboral e conflitos existenciais (Putriastuti \& Stasi, 2019; Seufert et al., 2021), em parte pela natureza dos tempos atuais, com abundância de informações, mudanças rápidas em tecnologia e ferramentas de representação social e uma nova expressividade, ainda não medida ou compreendida com a meta de realizar contribuições individuais em uma escala diferente das gerações anteriores e suas necessidades de exprimir opiniões (P21, 2019; Calvosa, 2021), fatos que justificam que sejam ouvidos e analisados como grupo, em seus anseios e aspirações, ao longo da graduação.

Nenhuma teoria de gestão parece ser adequada, até o momento, após análise de teorias vigentes, para liderar a geração do milênio de maneira ideal (Souza Neto \& Calvosa, 2006; Putriastuti \& Stasi, 2019). Por outro lado, quando há interação com outras pessoas e com o mundo, mesmo sem uma teoria balizante, as experiências geradas poderão contribuir para desenvolver 
um indivíduo de forma pessoal e profissional e permitir um olhar crítico em relação ao futuro, à visão de mundo e para dentro de si mesmo. Somos seres em construção que, quando devidamente estimulados, podemos ter nossos anseios e necessidades atendidos. A experiência de ingressar, cursar e conviver em uma instituição de ensino superior (IES) pode gerar um alto impacto, nesse sentido. Gerando vivências, conhecimentos, práticas, novas amizades (Teixeira et al., 2008), aprendizado sistemático ou não, comparações sociais, formação de metamodelos profissionais e de vida, que vão muito além da formação profissional, desencadeando diversas transformações nesse indivíduo. O ingressante de um curso superior, geralmente, apresenta algumas expectativas quanto às dificuldades que poderão surgir ao longo do curso e também sobre as possibilidades que a graduação pode proporcionar. Assim, ao propiciar espaços para instrução, debate e reflexão conjuntos, a sua trajetória na graduação poderá ser melhor aproveitada.

Com essa visão, este trabalho propõe apresentar e analisar um instrumento de socialização de conhecimento, mapeamento de carreira e aumento de interação entre os alunos (formação de rede) e os próprios alunos e alunos e profissionais de mercado, como forma de os preparar e os desenvolver, por meio para a sua formação profissional e pessoal plena. A Semana Acadêmica SIGICar - Semana Acadêmica de Integração, Gestão e Insights de Carreira é uma ação de extensão desenvolvida por professores (por meio de uma equipe acadêmica e uma equipe técnica), por organizadores, pelo Curso de Administração da UFRRJ e pelo Departamento de Ciências Administrativas - DCAd da UFRRJ, campus Seropédica / RJ. Contudo, extensível a todo o campi da UFRRJ, à comunidade acadêmica e ao curso EaD de Administração do CEDERJ, por meio do Programa de Extensão DEGECAR = Núcleo de Desenvolvimento e Gestão de Carreiras.

Socialmente e culturalmente, o que justifica a questão de pesquisa e a relevância do projeto e da pesquisa, os alunos de IES públicas não possuem variadas oportunidades de capacitação e de interação com profissionais do mercado de trabalho ou mesmo, com alunos de outros períodos, que podem ser referenciais para a sua adequada formação, por motivos que não cabem, por não ser o foco desse trabalho, desenvolver tal discussão. Entre outros desafios para promover a integração dos estudantes e lhes proporcionar impactos positivos na direção de mudanças transformadoras, apropriação de novos saberes e identificação de possíveis contradições inerentes à gestão de sua carreira, alguns mostram-se pujantes: as condições e restrições de conseguir espaço público adequado, a indevida divulgação do evento pela escassez de canais apropriados, as limitações tecnológicas da própria IES pública, a falta de verba para custear a vinda de profissionais (leia-se reembolso de transporte ou acomodação), o tempo não cedido pelos atores da própria IES, falta de engajamento, interesse e comprometimento de professores e alunos etc. Outra dificuldade também encontra-se na escassez de literatura acadêmica e científica sobre experiências de extensão e, sobretudo, análises de projetos e eventos envolvendo uma ação como uma semana acadêmica. Isso foi um fato motivador para os pesquisadores e atesta a originalidade do estudo.

Diante disso, a seguinte questão de pesquisa foi lançada: - Quais formatos, temas e ideários de carreira poderiam ser oferecidos aos estudantes de IES, no curso de Administração, para que o seu envolvimento seja mais participativo e essa ação de extensão consiga promover uma contribuição na formação profissional e pessoal dos alunos? O objetivo do trabalho foi identificar, entre os estudantes de Administração da UFRRJ e do CEDERJ, qual o modelo adequado, segundo as suas percepções, para a oferta de uma semana acadêmica que tivesse significado para a sua construção de carreira e seu desenvolvimento pessoal.

\section{Educação Profissional e o Modelo Mental do Estudante de IES}

Ingressar em uma IES pode ser uma experiência transformadora para um estudante, gerando repercussões de ordem psicológica e experiências importantes que podem impactar o seu sucesso acadêmico e o seu nível de profissionalização, mas também, outras camadas da vida. A forma como o aluno irá se integrar e participar de atividades no contexto do ensino superior farão diferença em sua formação profissional e em seu desenvolvimento psicossocial (Teixeira et al., 2008). A nova 
geração de alunos de ensino superior, nascidos sobretudo entre as décadas de 1990 e início da década de 2000, possuem como características dinâmicas questões como valores de autopreservação, necessidade de exprimir suas opiniões, alta competitividade e individualismo, em escala maior e mais significativa que as gerações anteriores (Luo, 2020), além de uma característica, já estudada, de relegar as suas decisões iniciais de carreira e de seu desenvolvimento para terceiros, como um mentor, um professor ou um gestor (Calvosa, 2008), buscando modelos de liderança e de influência em seu planejamento de vida (Calvosa et al., 2020).

A Educação Profissional e Tecnológica (EPT), segundo o Ministério da Educação e Cultura [MEC] (2022a) é "uma modalidade educacional prevista na Lei de Diretrizes e Bases da Educação Nacional (LDB) com a finalidade precípua de preparar 'para o exercício de profissões', contribuindo para que o cidadão possa se inserir e atuar no mundo do trabalho e na vida em sociedade". E são compostas de temas diversos e interligados, dentre os quais destaca-se o trabalho como princípio educativo e a formação integral (Coradini et al., 2020). Essa normatização, que apresenta-se como uma modalidade educacional, abrange cursos de qualificação e habilitação técnica, organizados para propiciar o aproveitamento contínuo e articulado dos estudos. A EPT prevê integração com os diferentes níveis e modalidades da Educação e às dimensões do trabalho, da ciência e da tecnologia, como, por exemplo, a articulação com a modalidade da educação de jovens e adultos, em órgãos normatizadores, que podem gerar EPT desde a 'qualificação profissional técnica' até o 'doutorado profissional', e construções ao longo da vida (MEC, 2022a). Isso mostra a preocupação do governo federal, principal ator formador de cidadãos, com o fomento e os instrumentos necessários para a construção de oportunidades, diálogos e construção de um modelo mental que permita a construção e a devolução à sociedade de cidadão capazes de gerar a interface necessária para interagir em um ambiente profissional complexo e de múltiplas oportunidades.

O avanço tecnológico, as mudanças na sociedade, os eventos culturais e os próprios esforços governamentais estão transformando a dinâmica do processo ensino/aprendizagem e o contexto educacional. O cenário proposto para uma educação superior participativa e empenhada com as novas tendências tecnológicas, sociais e profissionais deverá apresentar dinâmicas e oportunidades para ser atrativo para os estudantes das novas gerações, com suas idiossincrasias, gerando um ambiente de trocas, disponibilidade de múltiplas modalidades e plataformas de educação profissional, evitando frustrações, distâncias ou rupturas psicológicas e evasões. Os educadores deverão se adaptar às novas realidades, necessidades e circunstâncias em nome de um processo de ensino/aprendizagem de qualidade, de responsabilidade e de inclusão.

Os próprios estudantes, em uma visão abrangente e adequada, poderão fazer parte do processo de construção de diferentes espaços de aprendizagem, tendo como objetivo discutir a articulação entre as tecnologias educacionais (Santana, 2020). Uma tecnologia educacional não envolve, necessariamente, e pode ter nenhuma relação com gadgets, virtualidade e eletrônicos. Para Santos (2019), a tecnologia educacional "consiste no desenvolvimento de propostas de ações baseadas em disciplinas científicas que se referem às práticas de ensino que, incorporando todos os meios a seu alcance, dão conta dos fins da educação nos contextos sócio históricos que lhes conferem significação". É preciso refletir em como e nas formas que as tecnologias, em um contexto educacional, possam apresentar oportunidades de ensino, de aprendizagem e contribuições para a formação plena do estudante. Nessa nova relação demandada pela nova geração de alunos, o professor não atua (pelo menos no modelo mental do próprio aluno) como um informador ou um repositório de informações e conhecimentos. Antes, o professor apresenta-se (ou deveria se apresentar) como um facilitador, satisfazer ou levar o estudante a uma curiosidade, gerar um insight (Santos, 2019; Calvosa, 2008).

O conhecimento passa a ser construído a partir da compreensão das novas formas de comunicação e de como se produz e comunica valor. A tecnologia apresenta-se como um meio para gerar o conhecimento e adicionar interesse. O papel do professor de IES de acordo com o novo modelo mental dos estudantes também vem mudando. O docente deve ser o criador de ambientes de aprendizagem e facilitador do processo de aquisição de conhecimentos, deixando de fazer uso do papel de 
repassador de conhecimento. Para melhor atender ao processo de ensino/aprendizagem, o professor deverá ter uma postura de abertura, humanidade, ser um estimulador, valorizar a busca e democratizar a comunicação e as pesquisas, com interação e interatividade (Santana, 2020). Apresentando resultados que vão ao encontro do esperado, dos Santos (2019), em sua pesquisa, afirma que o uso constante dos recursos tecnológicos em atividades docentes permite o favorecimento da construção do conhecimento. E Teixeira et al. (2008) apontam que a atuação dos professores associada ao envolvimento dos alunos em atividades acadêmicas extraclasse favorecem a adaptação e o desenvolvimento profissional e pessoal desses últimos. Diante de todo o exposto, os atuais desafios da educação e as novas demandas em IES podem ser vistos no Quadro 1:

Quadro 1. Quinze Principais Desafios Atuais e Demandas da Educação em IES.

\begin{tabular}{|l|l|}
\hline $\mathbf{1}$ & Propor ambientes e espaços atrativos de interação para a coletividade de alunos \\
\hline $\mathbf{2}$ & Estabelecer e divulgar as tecnologias a serem utilizadas na relação de construção do conhecimento \\
\hline $\mathbf{3}$ & Ser um professor facilitador, não informador \\
\hline $\mathbf{4}$ & Gerar insights de carreira e instigar a curiosidade \\
\hline $\mathbf{5}$ & Comunicar valor e significado por meio de ações e iniciativas de aprendizagem \\
\hline $\mathbf{6}$ & Direcionar para o crescimento e desenvolvimento pessoal e profissional conjuntos \\
\hline $\mathbf{7}$ & Realizar mentoria \\
\hline $\mathbf{8}$ & Desenvolver um processo de educação profissional, com participação de atores de mercado de trabalho e da sociedade \\
\hline $\mathbf{9}$ & Permitir que o estudante faça parte do processo de criação e articulação do conhecimento \\
\hline $\mathbf{1 0}$ & Gerar um espaço para a expressão de opiniões e vontades, mas que iniba o caráter individualista \\
\hline $\mathbf{1 1}$ & Orientar a competitividade do aluno para um projeto profissional ou acadêmico \\
\hline $\mathbf{1 2}$ & Fomentar a integração dos alunos com outros alunos, de sua IES e de outras instituições \\
\hline $\mathbf{1 3}$ & Construir processos inovadores de ensino/aprendizagem \\
\hline $\mathbf{1 4}$ & Estimular o estudante a uma formação mais plena, além do ensino, envolvendo oportunidades de pesquisa de extensão \\
\hline $\mathbf{1 5}$ & Interagir com um modelo mental dos estudantes ainda em construção e não explicado por teoria que esgote o assunto ou aponte em \\
\hline
\end{tabular}

Fonte: Desenvolvido pelos autores, com base em Teixeira et al. (2008), Calvosa (2008), Santos (2019), Luo (2020), Leite et al. (2020), Santana (2020), Seufert et al. (2021), Calvosa (2021).

A Tabela 1 expõe, na visão dos autores, os desafios contemporâneos para docentes e discente, para a formação acadêmica, cidadã e profissional de excelência, que deverá atrair também atores externos à universidade, para uma correspondência de interesses, de expectativas e de oportunidades (Gouveia et al., 2009; Abdalla et al., 2013). Apesar de não ser classificado como uma política ou modalidade educacional de EPT, projetos e eventos de extensão, em um primeiro momento, parecem contribuir ou se alinhar com as novas propostas e desafios da educação superior em IES. Entre outros motivos, pela sua fluidez, por sua temporalidade, pela sua flexibilidade e seu caráter introdutório e socialmente contemplativo, no qual o seu conteúdo, formato, atividades, ingresso ou saída de atores, dinâmica e interações podem ser facilmente mudados e convertidos em formas mais interessantes e adaptadas a um público específico.

\section{Ações de Extensão como Suporte e Incentivo às Iniciativas de Educação}

Professores de IES enfrentam diversos desafios para tentar propor e alcançar um sistema de educação atrativa e de qualidade, o que envolve, entre outras questões, o próprio desinteresse atual do aluno (Coradini et al., 2020; Seufert et al., 2021). Não é tarefa fácil criar, com quantidade limitada de recursos, iniciativas isoladas, falta de apoio da própria instituição (em alguns casos), escassez de insumos, entre outros fatores, um ambiente de atratividade e de estímulo para os estudantes. Ao professor de IES não cabe "ensinar", pois aprendizagem em adultos é um processo de individual e voluntário - o estudante deve, primeiro, querer aprender, para que o processo seja iniciado. Porém, é possível e adequado que o professor lhe gere interesse, o estimule e comunique valor no conhecimento que passou a ser circulado em sala de aula ou em outro meio. Para Santos (2019), o professor deverá ajudar: 
"O estudante a desafiar regras, descobrir novos padrões de relações, improvisar e até adicionar novos detalhes a outros trabalhos, tornando-os inovadores e diferenciados, somando assim a sua aprendizagem” e, também, “conduzir o processo educacional, pois possuem práticas de produzir informação e divulgação em rede, construindo de forma sistemática e crítica o conhecimento".

Silliman et al. (2020) apontam em sua pesquisa que a aprendizagem experiencial e a reflexão crítica são mecanismos com maior probabilidade de resultar em mudanças de comportamento que promovem a transição e eficácia na carreira de um aluno, por exemplo, em um profissional eficaz. Nessa linha, Teixeira et al. (2008) destacam que as atividades acadêmicas não obrigatórias podem ocupar um destaque e ser uma estratégia para a adaptação do aluno de IES na nova realidade e experiência no qual passou a estar envolvido: a vida universitária. As atividades acadêmicas extras exigem e destacam um carácter de responsabilidade, estimulam a interação do aluno com outros aluno e com professores, apresentam projetos de pesquisa e de extensão, possibilita conhecer novas realidades e motiva os alunos em relação à vida acadêmica. Nesse sentindo, encontra-se nas ações de extensão, no âmbito de uma IES, espaço, oportunidade e flexibilidade para a proposição e sugestões de iniciativas que possam dar a liberdade aos professores de decisões de implantação de educacionais e tecnológicas. A Extensão, de forma geral, é a interação da universidade com a sociedade, na qual a primeira transmite conhecimentos acadêmico-científicos e a segunda transmite experiências vivenciais. As ações de extensão devem buscar solucionar problemas existentes, de interesse e necessidade da sociedade, ampliando a relação dessa com a Universidade. Podem envolver ações de conscientização, capacitação, difusão de informação, tecnologia e cultura, consultorias, emissão de laudos, entre outras. Segundo o MEC (2022b):

“[...] a Extensão Universitária sustenta-se principalmente em metodologias participativas, no formato investigaçãoação (ou pesquisa-ação), que priorizam métodos de análise inovadores, a participação dos atores sociais e o diálogo" e que "A primeira diretriz do Plano Nacional de Extensão diz respeito à indissociabilidade entre ensino, pesquisa e extensão, ela 'reafirma a Extensão Universitária como processo acadêmico'. Nessa perspectiva, o suposto é que as ações de extensão adquirem maior efetividade se estiverem vinculadas ao processo de formação de pessoas [...]" (Política Nacional de Extensão Universitária).

As ações de extensão deverão conter informações sobre a sua relevância e argumentação que as justifiquem, motivação para sua concretização e impactos esperados. Em uma ação de extensão bem-sucedida, tanto a academia quanto a sociedade aprendem, a interação incrementa o desenvolvimento de ambas, estabelecendo um ciclo virtuoso. Com essa visão, Castro Jr et al. (2020) defendem que projetos de extensão, palestras, contato com associações comercias, realização de semanas acadêmicas ou científicas são práticas que deveriam ser comuns nos cursos de graduação e agregam valor a todos os participantes, além de recepcionar bem novos alunos. Santos (2019) defende que a interatividade entre teoria e prática, envolvendo alunos e professores geram possibilidades de circulação de conhecimento, diminui as barreiras de aprendizagem, permite uma comunicação efetiva e positiva, promove caminhos valiosos e geram uma educação de qualidade. Nesse sentido, Santana (2020) mostra que uma visão pedagógica inovadora e bem aceita passa por estabelecer uma relação de afinidade com os alunos, procurando conhecê-los, seus gostos, visão futura e estímulo à participação, oportunidades que estão em evidência em ações de extensão. Ações de extensão dentro de um ambiente de uma IES pode desenvolver uma visão crítica dos conhecimentos teóricos aprendidos ao longo do curso, à medida que os alunos "medem” os seus conhecimentos, habilidades e atitudes, com as competências trazidas de fora da seu convívio acadêmico, por profissionais de mercado, professores de outras IES, professores ou agentes que estão a própria IES, mas não convivem academicamente com esses alunos, por ocuparem cargos administrativos ou serem de outros cursos. Existe também um ganho social, em formação de rede, e cultural, em conhecer novas realidades, saberes, visões de mundo. O participante pode passar a ter um olhar mais contemplativo e profundo sobre a sua profissão, sobre a sociedade ou sobre si mesmo. 
O objeto de estudo dessa proposta e da visão contida nesse trabalho foi a análise de um projeto de extensão com evento agregado chamado Semana Acadêmica SIGICar - Semana Acadêmica de Integração, Gestão e Insights de Carreira. Uma ação de extensão recente, instituída no ano de 2020, por meio do Programa de Extensão DEGECAR - Núcleo de Desenvolvimento e Gestão de Carreiras da UFRRJ. A sua proposição, também envolveu gerar um espaço de construção de carreira, competências necessárias para a formação acadêmica plena e aumento da empregabilidade, sobretudo, dos alunos de Administração da UFRRJ e do CEDERJ.

\section{Semana Acadêmica em Administração: o caso SIGICar}

Semana Acadêmica é uma ação de extensão que possui como objetivo primário gerar uma maior integração entre professores, alunos, profissionais de mercado e a comunidade acadêmica, em geral. Ela pode apresentar atividades com ênfase no ensino, na interatividade e na capacitação, tais como: palestras, mesas redondas, fóruns, seminários, simpósios, estudos de caso, dinâmicas, apresentação de projetos de pesquisa e de extensão, entre outras iniciativas, por meio de atividades programadas. Tais atividades são ministradas pelos professores da IES proponente e convidados (ex-alunos, consultores de mercado, gestores, representantes de vários seguimentos, professores de outros cursos ou outras IES, professores que ocupam cargos administrativos etc.) Possui um tema central e um local definido, geralmente, no interior da IES proponente. Algumas funcionam em um formato misto, entre atividades presenciais e virtuais, o que agrada grande parcela da atual geração de estudantes. Suas atividades são planejadas por meio de uma proposta pedagógica definida pela organização do evento. Pode (e deve) ter a participação dos próprios alunos da instituição em sua concepção e organização, incluindo atores externos à universidade (Gouveia et al., 2009).

A Semana Acadêmica SIGICar é um evento realizado em substituição ao formato anterior, sazonal, promovido eventualmente e sem a adesão de grande parte do corpo docente do Departamento de Ciências Administrativas (DCAdUFRRJ). Nesse novo formato, os proponentes do projeto, os professores do DCAd em conjunto com o Diretório Estudantil do Curso e com a Coordenação do Curso de Administração, propõe e promovem, com convidados externos, ex-alunos, palestrantes de mercado, professores de outras instituições e representantes de órgãos públicos e privados, temas e aplicações de assuntos ligados às práticas de Administração e ao desenvolvimento de carreira dos alunos de Administração. O evento é gratuito e direcionado aos alunos dos cursos diurno e noturno de Administração e aos alunos da modalidade EaD em Administração do CEDERJ, um consórcio do Estado do Rio de Janeiro em conjunto com as universidades públicas fluminenses. Porém, extensível a toda a comunidade acadêmica, principalmente para os alunos do Instituto de Ciências Sociais Aplicadas - ICSA-UFRRJ. Todas as suas iniciativas foram divulgados de forma presencial pela coordenação do curso, em palestras promovidas pelo Programa de Extensão DEGECAR, em mailings para atuais e ex-alunos e pelas redes sociais. Em cada uma das três edições avaliadas, alvo das investigações desse trabalho, o evento atraiu entre 90 e 130 discentes por edição, entre os mais de 2.000 convites realizados por edição, por meio de todas as iniciativas. Entre os seus objetivos estão: aumentar a interação dos alunos entre si e com os professores, difundir os estudos da área de Ciências Administrativas, divulgar conhecimento científico e acadêmico de fronteira, com a divulgação das pesquisas e projetos de pesquisas vigentes no DCAd, aumentar a empregabilidade do estudante, ajudar na construção e no desenvolvimento de carreira, divulgar oportunidades de estágio, entre outros.

\section{Método}

Os cursos de Administração da UFRRJ contam com cerca de 420 alunos, no campus Seropédica, na modalidade presencial. E as edições de 2020.I e 2020.II foram essencialmente direcionadas para os alunos da modalidade presencial, para que houvesse uma curva de aprendizagem e os organizadores pudessem, ao longo do tempo, prever, organizar e planejar os 
caminhos adequados para edições mais contemplativas e abertas para um público maior. A edição de 2021.I já contou com uma divulgação maior, direcionada com muitos esforços também para a comunidade acadêmica, outras instituições parceiras e para os alunos na modalidade de ensino EaD. Essa pesquisa contempla essas três última edições - todas realizadas durante a pandemia de COVID 19. Um artigo científico anterior, envolvendo apenas a edição de 2020.I foi pulicado em um evento científico em Administração. Contudo, os resultados da comparação dos dois trabalhos não apresentou tantas alterações.

Um formulário eletrônico do Google Forms foi disponibilizado pelo mailing da coordenação, em formato de survey, convidando a totalidade dos alunos para a participação da Semana Acadêmica. Apesar de um grande estímulo e o reforço da para a participação tanto na semana acadêmica, quanto na participação dessa pesquisa, apenas 71 alunos distintos participaram da pesquisa direcionada nos três momentos, envolvendo o período entre março de 2020 e agosto de 2021. Cerca de 45 alunos participaram de duas ou mais semanas acadêmicas SIGICar e responderam a duas ou três vezes à pesquisa. Mas, esses questionários tiveram que ser descartados, para não criar um viés na pesquisa proposta. Alguns fatores analisados que justificaram a baixa adesão de participação podem ter sido o início a instabilidade gerada com a pandemia global de COVID 19, a incerteza se o período letivo seria iniciado nas universidades federais e o impacto psicológico e emocional da própria pandemia sobre os participantes da semana acadêmica, estimulados a participarem da pesquisa.

Outra pesquisa foi estimulada e realizada com membros futuros participantes da SIGICar, para que os resultados fossem comparados e apontassem uma direção compartilhada para a elaboração das próximas edições desse evento de extensão. Essa segunda amostra foi composta de 97 alunos de Administração da UFRRJ (campus Seropédica). Dessa forma, a amostra total válida, considerada para os fins dessa pesquisa foi de 168 alunos, divididos em dois estratos: participantes e futuros participantes da semana acadêmica SIGICar, entre alunos do sistema presencial e EaD. A pesquisa teve um carácter qualitativo, para que se pudesse compreender um conjunto de significados, os motivos e as aspirações da amostra selecionada, representativa de uma população de discentes e interessados. Com isso pretende-se melhor entender os processos e os fenômenos (Minayo, 2002), além de ajudar a direcionar futuros esforços e recursos. E também versou sobre a desconstrução das características técnicas e comportamentais ligadas às personagens e personalidades admiradas pelos alunos. Além de uma estatística descritiva sobre os dados sócio demográficos e acadêmicos. Finalmente, para completar o escopo desenhado para a abordagem qualitativa, uma Análise de Conteúdo foi promovida, com o objetivo e interpretar e gerar inferências sobre a opinião e perspectivas dos alunos sobre os objetos de observação semana acadêmica e construção de carreira, entre os participantes e os não participantes da SIGICar (Bardin, 2010).

\section{Análises e Considerações}

O Quadro 2 aponta as principais características da amostra de participante da Semana Acadêmica SIGICar (todos alunos do ensino presencial em Administração da UFRRJ):

Quadro 2. Características da Amostra dos Participantes da Semana Acadêmica SIGICar.

\begin{tabular}{|c|c|c|c|c|c|c|}
\hline \multirow{2}{*}{ Gênero } & \multicolumn{2}{|c|}{ Feminino } & \multicolumn{2}{|c|}{ Masculino } & \multicolumn{2}{|c|}{ Total } \\
\hline & \multicolumn{2}{|c|}{$41(57,7 \%)$} & \multicolumn{2}{|c|}{$30(42,3 \%)$} & \multirow{2}{*}{\multicolumn{2}{|c|}{$71(100 \%)$}} \\
\hline \multirow{2}{*}{ Idade do Amostra (em anos) } & Média & Moda & Média & Moda & & \\
\hline & 24,4 & 20 & 26,1 & 22 & \multicolumn{2}{|c|}{$25.6 / 20$} \\
\hline \multirow{4}{*}{ Experiência profissional (em meses) } & Sim & Não & Sim & Não & Sim & Não \\
\hline & $13(32 \%)$ & $28(68 \%)$ & $21(70 \%)$ & $9(30 \%)$ & $34(48 \%)$ & $37(52 \%)$ \\
\hline & \multicolumn{2}{|c|}{ Média } & \multicolumn{2}{|c|}{ Média } & \multicolumn{2}{|c|}{ Média } \\
\hline & \multicolumn{2}{|c|}{22} & \multicolumn{2}{|c|}{40} & \multirow{2}{*}{\multicolumn{2}{|c|}{$\begin{array}{c}31 \\
\text { Média / Moda }\end{array}$}} \\
\hline \multirow{2}{*}{$\begin{array}{l}\text { Movimentações de carreira para } \\
\text { atingir o seu objetivo profissional }\end{array}$} & Média & Moda & Média & Moda & & \\
\hline & 3 & 3 & 4 & 3 & \multicolumn{2}{|c|}{$3,4 / 3$} \\
\hline
\end{tabular}

Fonte: Dados da pesquisa. 
Na Tabela 2, as características da amostra de participantes da Semana Acadêmica são: essa amostra é constituída de (i) em sua maior parte de solteiros, brasileiros e sem filhos (64\%); (ii) pertencem ao curso de graduação em Administração (100\%); (iii) residem no Estado do Rio de Janeiro (96\%); (iv) não haviam participado de uma semana acadêmica (92\%); (v) possuem pouca experiência profissional, principalmente, expressa em estágios supervisionados ou trabalhos informais experiência profissional; (vi) não exerceram atividade de gestão, coordenação ou chefia (93\%). 19 respondentes (27\%) encontram-se no primeiro ou segundo período do curso, e sua maior parte, 34 respondentes (48\%) encontram-se no terceiro ou quarto período do curso, mostrando que a adesão à semana acadêmica ocorre, majoritariamente, entre os alunos que se encontram no primeiro ciclo (ou metade da graduação). Digno de nota é que pelo fato do evento ser virtual e com maiores concentrações de atividades noturnas, o aluno estar inserido no mercado de trabalho, teoricamente, não atrapalharia a sua participação. Uma constatação, por meio de uma consideração, foi que os organizadores perceberam baixa participação e envolvimento dos alunos na programação noturna, com grande destaque e apoio para as atividades vespertinas.

Um conjunto de informações colhidas na pesquisa permitiu mostrar uma visão idealizada ou não estruturada sobre a interação dos participantes com o mercado de trabalho e o planejamento de carreira. A Figura 1 apresenta os desejos dos participante da SIGICar em relação à sua projeção de carreira, após formados.

Figura 1. Desejos dos Participantes da SIGICar em relação à sua Carreira.

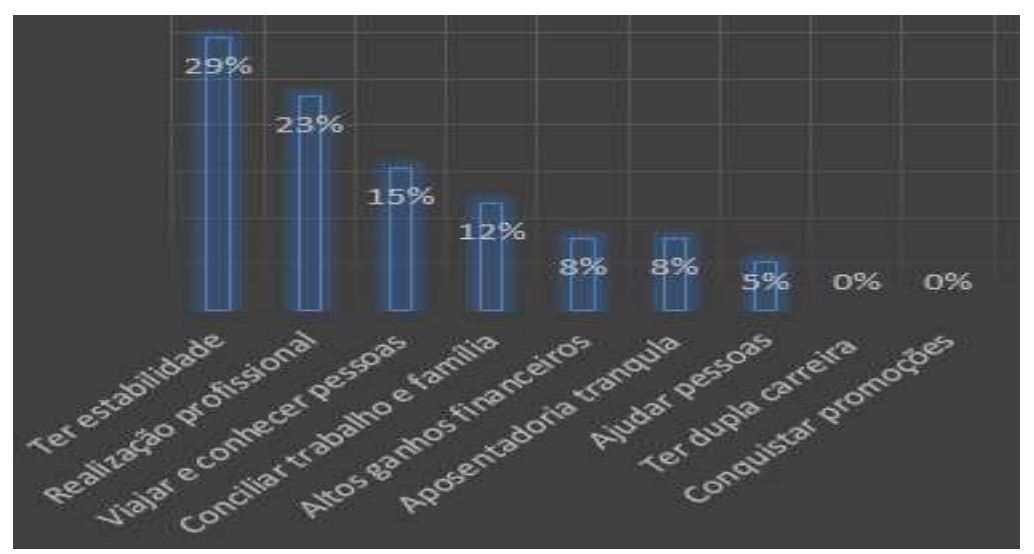

Fonte: Dados da pesquisa.

Ao analisar a Figura 1 pode ser constatado que a falta de rendimentos e à expectativa em relação ao primeiro emprego formal podem ter contribuído para que o resultado da variável 'ter estabilidade' aparecesse em primeiro lugar. Tradicionalmente, por ser uma amostra com mais indivíduos da Geração Z, variáveis como ‘viajar e conhecer pessoas’ e ‘altos ganhos financeiros' costumam aparecer dentre as primeiras opções (Xavier et al., 2012). Outro fator ligado à variável considerada primária, dentre os elementos da amostra, parece atender "às preocupações mais prementes do estudante de Administração, que são o receio de ficar desempregado ou não saber qual rumo tomar após o término da graduação" (Calvosa, 2008, p. 201). A variável 'realização profissional' aparecer com um percentual alto, em segundo lugar, está dentro dos parâmetros esperados e costuma aparecer entre as primeiras opções, apesar de o estudante de Administração relegar as suas decisões iniciais de carreira para terceiros, como um mentor, professor ou gestor (Mello et al., 2009, Xavier, Espirito Santo, Calvosa, 2011).

Com o objetivo de avaliar a iniciativa de educação profissional e sua tecnologia de execução pelos próprios participantes da Semana Acadêmica, a pesquisa contemplou variáveis que metrificaram a predileção de pontos fundamentais de sua realização (da edição 2020.I) e relevantes para as próximas edições, com o objetivo de ajudar na composição das novas edições. Os principais resultados encontram-se no Quadro 3: 
Quadro 3. Avaliação da Semana Acadêmica SIGICar pelos próprios Participantes.

\begin{tabular}{|l|l|}
\hline \multicolumn{1}{|c|}{ Proposição } & Percentual \\
\hline Achei o conteúdo totalmente adequado para uma semana acadêmica & $97 \%$ \\
\hline Achei o formato e a programação ideais para uma semana acadêmica & \\
\hline Os palestrantes foram pontuais e estavam presentes, permitindo a interação com o público & $94 \%$ \\
\hline A qualidade dos palestrantes atingiu totalmente às minhas expectativas & $82 \%$ \\
\hline Penso ser adequado uma semana acadêmica com programação na parte da tarde, preferencialmente & $65 \%$ \\
\hline Participei de até 60\% das atividades que gostaria de participar & $65 \%$ \\
\hline Os tipos de atividades atingiram totalmente às minhas expectativas & $64 \%$ \\
\hline As atividades programadas (excetuando as palestras) atenderam totalmente às minhas expectativas & $48 \%$ \\
\hline
\end{tabular}

Fonte: Dados da pesquisa.

De acordo com a Tabela 3, na avaliação dos alunos, sobre a programação e a realização da SIGICar, somadas as três edições, o conteúdo, o formato e a programação da semana acadêmica foram os parâmetros mais aprovados pelos alunos, somada à pontualidade e ao compromisso estabelecido pelos palestrantes. Esses foram os maiores acertos e pontos altos desse evento de extensão. Por outro lado, os menores índices da aprovação concentraram-se nos tipos de atividades oferecidas pelo evento e das atividades programadas (algumas delas exigiam uma postura mais ativa do aluno, com interação e exposição, como workshops e dinâmicas). Porém, as palestras, pelo visto a modalidade mais aprovada pelos alunos, concentraram cerca de $70 \%$ da metodologia de ensino-aprendizagem utilizada. Com uma consideração, em forma de crítica a todo o conjunto docente e discente, também é a que permite uma postura mais passiva (ou totalmente) dos alunos.

Os respondentes, explicado pela maior parte da amostra ser dos períodos iniciais do curso e não estar inserido no mercado de trabalho, gostariam que as atividades e palestras fossem concentradas senão somente, pelo menos de forma majoritária, no período vespertino. Na prática, as atividades programadas não tiveram boa adesão dos participantes, sendo algumas canceladas por falta de público, diretriz que servirá para ajudar na composição da oferta das próximas atividades programadas, nas próximas edições da SIGICar, como a revisão de temas a serem oferecidos, formato e período do dia de suas realizações.

Os participantes da Semana Acadêmica SIGICar, segundo a pesquisa, esperam encontrar os seguintes temas nas palestras, seminários e atividades programadas nas próximas edições: mercado de trabalho e carreira do futuro administrador, gestão empresarial e empreendedorismo, liderança e orientação profissional, curiosidades sobre a área acadêmica e a pósgraduação, mercado financeiro e economia, nessa ordem. Para todos os participantes, a SIGICar atingiu seus objetivos de capacitação. Entre eles 57\% possuem o interesse de que na próxima edição, os temas 'mercado de trabalho' ou 'gestão de carreira’ sejam evidenciados. A Análise de Conteúdo realizada com a amostra de participantes registrou, entre outras opiniões, a contagem frequencial (unidade de significação a codificar correspondente ao segmento de conteúdo a considerar como unidade base) e a exploração do material (para possibilitar as interpretações e inferências, de forma analítica, a respeito do material textual coletado) - corpus (Bardin, 2010; Mozzato \& Grzybovski, 2011), para melhor compreensão da capacidade instrucional dessa iniciativa de educação profissional. De forma reducionista e simplificada, os seus principais pontos foram registrados no Quadro 4: 
Quadro 4. Principais Pontos da Análise de Conteúdo direcionada aos Participantes da SIGICar.

\begin{tabular}{|c|c|c|}
\hline Conteúdo da Questão & $\begin{array}{c}\text { Contagem } \\
\text { Frequencial }\end{array}$ & Unidade de Contexto \\
\hline $\begin{array}{l}\text { Sobre o interesse em palestrantes } \\
\text { externos à universidade, } \\
\text { sobretudo, gestores } \\
\text { organizacionais }\end{array}$ & 22 & $\begin{array}{l}\text { "[...] já ouvimos os professores nas aulas". } \\
\text { "[...] seria interessante trazer palestrantes de fora do curso de Administração". } \\
\text { "[...] eu gostaria que os futuros empregadores falassem para a gente e trouxessem } \\
\text { oportunidades de estágio". }\end{array}$ \\
\hline $\begin{array}{l}\text { Sobre o período da tarde ou da } \\
\text { noite ser o mais adequado para a } \\
\text { realização de atividades da } \\
\text { SIGICar }\end{array}$ & 18 & $\begin{array}{l}\text { "[...] na parte da tarde estou trabalhando". } \\
\text { "[...] as palestras eram um pouco tardes e infelizmente não pude comparecer em } \\
\text { todas por esse motivo". } \\
\text { "[...] como eu trabalho ficou cansativo acompanhar todo os dias à noite". } \\
\text { "[...] à noite, eu programo para ficar com a minha família". }\end{array}$ \\
\hline $\begin{array}{l}\text { Sobre a não participação em } \\
\text { distintos tipos de atividades e } \\
\text { em atividades programadas }\end{array}$ & 11 & $\begin{array}{l}\text { "[...] não gosto quando tenho que me expressar em público". } \\
\text { "[...] fico constrangida quando chama o meu nome". } \\
\text { "[...] não foi compartilhado um material para melhor nos preparar para a atividade". }\end{array}$ \\
\hline $\begin{array}{c}\text { Sobre a não participação em } \\
\text { atividades que gostaria de participar }\end{array}$ & 8 & $\begin{array}{l}\text { "[...] atividades em horários avançados são ruins para quem mora longe". } \\
\text { "[...] alguns professores mantiveram as aulas". }\end{array}$ \\
\hline $\begin{array}{c}\text { Sobre a maior concentração } \\
\text { de atividades no formato de } \\
\text { palestras ou seminários }\end{array}$ & 4 & $\begin{array}{l}\text { "[...] poderiam ter formatos diferentes de atividades, além de principalmente } \\
\text { palestras". }\end{array}$ \\
\hline
\end{tabular}

Fonte: Dados da pesquisa.

Sobre a Tabela 4, a inferência e a interpretação das principais passagens da Análise de Conteúdo condensam a opinião e comunicam que a organização do evento deverá flexibilizar algumas atividades e adaptar-se, dentro do possível, para que essa parcela do público seja melhor contemplada e atendida para novas edições do evento. Foi percebido que a organização do evento deverá caso possível, trazer palestrantes externos à universidade, sobretudo, externos ao curso de Administração para a realização das palestras e das demais atividades. Principalmente, gestores de mercado. O que gera um verdadeiro desafio para o atual cenário da educação superior (Greff do Amaral et al., 2020) e para a organização do evento, que não conta com apoio financeiro, financiamento ou atividade de fomento de nenhum órgão externo e nem da própria universidade, atualmente. E, em diversos momentos, corre todo o risco de inovar, de planejar e de conceber novas oportunidades sem o apoio das devidas políticas públicas (Gatti, 2021), em alguns casos passados, custeando do próprio bolso do(s) organizador(es), o combustível e um jantar simbólico pela gentileza de um palestrante externo conectado à sua rede de relacionamentos aceitar o convite (apelo) de um docente da universidade. Como diretrizes da organização, para tentar tender aos anseios desse grupo, será analisada a viabilidade, caso possível, de oferecer o material instrucional com antecedência e dimensionar atividades na parte da tarde para alunos de determinado ciclo profissional e na parte da noite, para alunos mais maduros, já inseridos no mercado de trabalho e com carreiras mais consolidadas. Alguns resultados aparentemente antagônicos na análise de conteúdo podem ser fruto da participação parcial da maior parte dos estudantes, que participou de um dia, mas em outro, com uma configuração diferente, não teve acesso. Por isso, alguma dificuldade de avaliar o evento como um todo.

Finalmente, sobre os variáveis de interesse para a empregabilidade do graduando em Administração da UFRRJ, a sua construção de carreira e as competências necessárias para a formação de uma gestão eficaz, segundo suas percepções, os resultados mais expressivos foram: (i) as principais características que um estudante precisa possuir são: exercer liderança, saber se comunicar, ser organizado e eficiente, nessa ordem; (ii) as principais características que um gestor precisa possuir são: ter empatia, ter foco e organização, ter conhecimento e bom relacionamento interpessoal, nessa ordem; (iii) a cantora Anitta foi a principal personalidade citada pelo grupo, como modelo de gestão empresarial e de gestão de carreira, enquanto a Apple, a empresa mais admirada. Os pesquisadores buscaram comparar a experiência dos participantes da semana acadêmica com as expectativas dos futuros participantes da SIGICar. Dessa forma, todo o caminho anterior foi novamente percorrido com a nova amostra. A seguir, o Quadro 5 aponta as principais características registradas do futuros participantes da referida semana acadêmica (64\% dos alunos do ensino EaD em Administração da UFRRJ, o CEDERJ): 
Quadro 5. Características da Amostra de Futuros Participantes da SIGICar.

\begin{tabular}{|c|c|c|c|c|c|c|}
\hline \multirow[b]{2}{*}{ Gênero } & \multicolumn{2}{|c|}{ Feminino } & \multicolumn{2}{|c|}{ Masculino } & \multicolumn{2}{|c|}{ Total } \\
\hline & \multicolumn{2}{|c|}{$58(60 \%)$} & \multicolumn{2}{|c|}{$39(40 \%)$} & \multirow{2}{*}{\multicolumn{2}{|c|}{$\begin{array}{c}97(100 \%) \\
\text { Média / Moda } \\
\end{array}$}} \\
\hline \multirow{2}{*}{ Idade do Amostra (em anos) } & Média & Moda & Média & Moda & & \\
\hline & 30,7 & 24 & 37,2 & 29 & \multicolumn{2}{|c|}{$33,7 / 24$} \\
\hline \multirow{4}{*}{ Experiência profissional (em anos) } & Sim & Não & Sim & Não & Sim & Não \\
\hline & $41(71 \%)$ & $17(29 \%)$ & $32(82 \%)$ & $7(18 \%)$ & $73(76 \%)$ & $9(24 \%)$ \\
\hline & \multicolumn{2}{|c|}{ Média } & \multicolumn{2}{|c|}{ Média } & \multicolumn{2}{|c|}{ Média } \\
\hline & \multicolumn{2}{|c|}{9,1} & \multicolumn{2}{|c|}{15,2} & \multicolumn{2}{|c|}{12,0} \\
\hline \multirow{2}{*}{$\begin{array}{l}\text { Movimentações de carreira para } \\
\text { atingir o seu objetivo profissional }\end{array}$} & Média & Moda & Média & Moda & \multicolumn{2}{|c|}{ Média / Moda } \\
\hline & 3 & 2 & 3 & 3 & \multicolumn{2}{|c|}{$3 / 2$} \\
\hline
\end{tabular}

Fonte: Dados da pesquisa.

Ao analisar a Tabela 5, algumas características dessa amostra são: (i) brasileiros (100\%), sobretudo casados (52\%) e sem filhos (61\%); (ii) pertencem ao curso de graduação em Administração (100\%); (iii) 45\% estão matriculados até o quarto período do curso de Administração; (iv) $49 \%$ já participaram anteriormente de uma semana acadêmica; (v) $11 \%$ possuem outra graduação completa ou pós-graduação; (vi) a maior parte reside no Estado do Rio de Janeiro (93\%); (vii) 28\% acreditam que o seu gestor imediato participaria de um evento de extensão futuro na UFRRJ, caso convidado formalmente pelos organizadores; (viii) $76 \%$ possuem experiência profissional com uma média de 12,0 anos de ocupação em cargos formais no mercado de trabalho; (ix) 24\% são atualmente gestores ou já foram em outra ocasião. Uma consideração relevante sobre esses dados é que nesta amostra, diferente da outra, muitos alunos de $\mathrm{EaD}$ (cerca de $60 \%$ da amostra) participaram como respondentes. O que fez com que a média de idade, de experiência profissional e de maturidade de carreira aumentasse. Esses fatos, em conjunto, mostram uma visão da amostra mais realística do mercado trabalho e que compreendem melhor um programa direcionado de educação profissional e as suas tecnologias educacionais envolvidas no planejamento e execução de um evento de extensão, quando comparado à outra.

A análise da Figura 2 permite registrar os desejos dos futuros participantes da Semana Acadêmica SIGICar em relação à sua projeção de carreira, após formados em Administração.

Figura 2. Desejos dos Futuros Participantes da SIGICar em relação à sua Carreira.

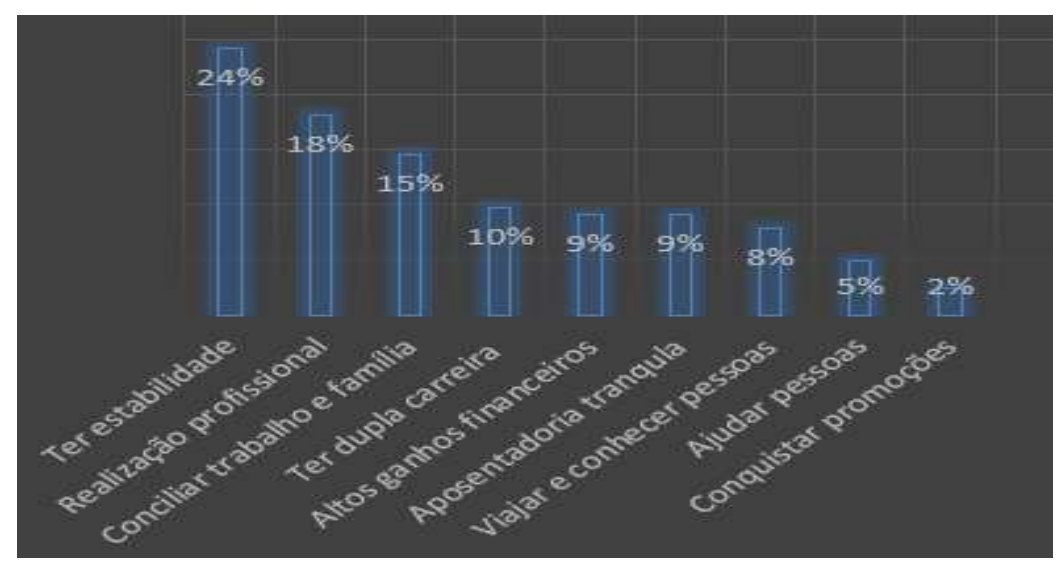

Fonte: Dados da pesquisa.

As duas primeiras variáveis em ambas as amostras mantiveram as mesmas, apesar de uma diferença de idade média de 7 anos entre as amostras e de 10 anos de experiência profissional. Talvez as diferenças entre as amostras de idade, experiência profissional e posicionamento no curso de Administração não sejam tão significativas a ponto de refletirem aspirações distintas em um planejamento de vida ou profissional, quando comparadas com outras pesquisas. A principal diferença está na variável 'ter dupla carreira', que na amostra de futuros participantes aparece em quarto lugar de interesse 
(enquanto na de participantes aparece em oitavo), ponto mais comum em indivíduos com carreira já consolidada e gestores (ou pessoas com a grande desenvolvimento organizacional) (Calvosa, 2021). Contrariando a literatura, a amostra de futuros participantes, pertencente à Geração Y, parece dar pouca importância para uma rápida promoção e projeção de carreira (Xavier et al., 2012).

Com o objetivo de avaliar uma proposta de educação profissional e sua tecnologia de execução para atender aos anseios de um futuro público participante (nas edições seguintes da SIGICar), a pesquisa contemplou variáveis que metrificaram a predileção de pontos fundamentais para realização de novas edições da semana acadêmica entre os futuros participantes. Os principais resultados encontram-se no Quadro 6:

Quadro 6. Intencionalidades sobre a Participação em uma Futura Edição da SIGICar.

\begin{tabular}{|l|c|}
\hline \multicolumn{1}{|c|}{ Proposição } & Percentual \\
\hline Sobre os palestrantes, o ideal seria uma proporcionalidade entre professores do curso e profissionais de mercado & $90 \%$ \\
\hline $\begin{array}{l}\text { Sobre a sua futura participação na semana acadêmica, o meu desejo seria participar senão de todas, pelo menos de } \\
\text { das atividades propostas }\end{array}$ & $84 \%$ \\
\hline Sobre as atividades programadas deveriam ocorrer de forma virtual & $70 \%$ \\
\hline Uma programação com três dias de duração seria ideal (o formato atual é quatro dias de duração) & $66 \%$ \\
\hline A programação deverá promover, principalmente, palestras, oportunidades de estágio e palestrantes de mercado & $55 \%$ \\
\hline Principal forma de instruir na semana acadêmica deveria ser palestras proferidas com a interação do público & $39 \%$ \\
\hline Sobre as atividades programadas deveriam ocorrer presenciais no horário da tarde & $30 \%$ \\
\hline
\end{tabular}

Fonte: Dados da pesquisa.

Percebe-se, no exame da Tabela 6, que os futuros participantes da Semana Acadêmica SIGICar esperam participar de atividades com os professores do curso e com profissionais de mercado, e desejam apoiar a maior parte das atividades programadas. Porém, parecem rejeitar atividades que contemplem a participação do público, de forma ativa. Provavelmente, por proporcionalmente e de modo absoluto estarem mais envolvidos com o mercado de trabalho também buscam maiores instruções, capacitações e oportunidades com ofertas de emprego, com interesse baixo em ofertas de estágio.

Essa amostra valorizou os seguintes temas a serem contemplados nas futuras palestras, seminários e atividades programadas: planejamento profissional; gestão de carreira e mercado de trabalho; mercado financeiro; novos cenários e mercado pós-pandemia; e gestão de pessoas e empresarial, nessa ordem.

As principais organizações citadas como relevantes a serem convidadas para a participação em um próximo evento foram: AMBEV, Coca-Cola, Microsoft e algumas empresas de pequeno porte dos quais pertencem. Para esse grupo, as personalidades conhecidas que expressam um modelo de gestão ou liderança ideal são Silvio Santos, Luiza Trajano e Bill Gates. E sobre as empresas competitivas, orientadas para o mercado mais admirada no momento são: Google, Amazon e Magazine Luiza, na quais gostariam de trabalhar.

O Quadro 7, traz os principais pontos sobre a Análise de Conteúdo promovida entre os futuros participantes da semana acadêmica: 
Quadro 7. Principais Pontos da Análise de Conteúdo direcionada aos Futuros Participantes da SIGICar.

\begin{tabular}{|c|c|c|}
\hline Conteúdo da Questão & $\begin{array}{c}\text { Contagem } \\
\text { Frequencial }\end{array}$ & Unidade de Contexto \\
\hline $\begin{array}{l}\text { Sobre o desejo de apoiar as } \\
\text { atividades propostas nas futuras } \\
\text { semanas acadêmicas }\end{array}$ & 34 & $\begin{array}{l}\text { "[...] somos carentes de atividades de inclusão". } \\
\text { "[...] as atividades servirão para descontar horas complementares? Caso sim, eu } \\
\text { quero participar e sei que a minha turma também". } \\
\text { "[...] podem ser sugeridos temas de interesses dos alunos? Acho que assim os alunos } \\
\text { se interessariam mais". } \\
\text { "[...] elas tem que ser em horários flexíveis para que os alunos que trabalham possam } \\
\text { participar". }\end{array}$ \\
\hline $\begin{array}{l}\text { Sobre o interesse em palestrantes } \\
\text { externos à universidade, } \\
\text { juntamente, com professores }\end{array}$ & 29 & $\begin{array}{l}\text { "[...] por ser do EaD, eu não conheço a maior parte dos meus professores". } \\
\text { "[...] seria uma boa oportunidade para fazer uma atividade com a turma toda e com } \\
\text { os professores do curso". } \\
\text { "[...] nas palestras poderiam ser abordadas oportunidades de emprego por parte dos } \\
\text { profissionais de mercado". } \\
\text { "[...] profissionais de mercado podem oferecer uma visão de mercado de trabalho } \\
\text { diferente dos professores". }\end{array}$ \\
\hline $\begin{array}{l}\text { Sobre se as atividades } \\
\text { programadas deveriam ser } \\
\text { presenciais ou virtuais }\end{array}$ & 20 & $\begin{array}{l}\text { "[...] eu não consigo me concentram em atividades virtuais". } \\
\text { "[...] devem ser virtuais, para economizar dinheiro de deslocamento e tempo". } \\
\text { "[...] eu prefiro virtuais, mas com a liberação de aula pelos professores". } \\
\text { "[...] já estou acostumado a atividades virtuais por ser do EaD e acho que o futuro } \\
\text { tenderá para mais atividades dessa forma". }\end{array}$ \\
\hline $\begin{array}{l}\text { Sobre o período da tarde ou da } \\
\text { noite ser o mais adequado para a } \\
\text { realização de atividades da } \\
\text { SIGICar }\end{array}$ & 20 & $\begin{array}{l}\text { "[...] eu trabalho em tempo integral". } \\
\text { "[...] só participarei se for na parte da noite". } \\
\text { "[...] na parte da tarde é melhor porque libera o aluno para ir para casa mais cedo" } \\
\text { "[...] se for de tarde não participarei". }\end{array}$ \\
\hline $\begin{array}{l}\text { Sobre a não participação em } \\
\text { distintos tipos de atividades e em } \\
\text { atividades programadas }\end{array}$ & 9 & $\begin{array}{l}\text { "[...] Eu tenho vergonha de falar em público". } \\
\text { "[...] acho que a própria pessoa deveria escolher com antecedência se gostaria ou não } \\
\text { de falar". }\end{array}$ \\
\hline $\begin{array}{l}\text { Sobre a participação em } \\
\text { distintos tipos de atividades e } \\
\text { em atividades programadas }\end{array}$ & 9 & $\begin{array}{l}\text { "[...] queria um incentivo para aprender com a ajuda da turma e poder me expressar, } \\
\text { já que o EaD é muito solitário". } \\
\text { "[...] as atividades com interação animam a gente". } \\
\text { "[...] não tenho problemas quando pedem para que eu fale em público". }\end{array}$ \\
\hline
\end{tabular}

Fonte: Dados da pesquisa.

Sobre a Tabela 7, a inferência e a interpretação das principais passagens da Análise de Conteúdo condensam a opinião e comunicam o desejo dos alunos em participar e apoiar as atividades propostas, a didática apresentada e a opção mista de palestrantes e facilitadores das atividades entre os professores do curso e profissionais de mercado.

Uma consideração relevante é que os alunos do EaD não possuem contato presencial (e muitas vezes nem virtual), apenas remoto por atividades assíncronas, com os seus professores de curso. O que gera uma curiosidade e interesse em maior interação com esse grupo.

Os futuros participantes oriundos do presencial tendem a buscar atividades complementares e de extensão mais presenciais, em relação aos oriundos do EaD. E, também, buscam atividades na parte da tarde caso sejam pode períodos iniciais do curso. Por outro lado, os alunos do EaD preferem atividades virtuais, independentemente do período.

Os alunos do EaD buscam mais atividades com interação, quando comparados com os do presencial, mas essa variável tem maior relação com a idade do aluno. Isolando a variável idade percebe-se que alunos com mais idade e com maior vivência profissional estão no grupo que possuem menores dificuldades de interagir, falar em público e ser questionados.

\subsection{Achados e Tendências das Amostras}

Com o objetivo de melhor oferecer um evento extensionista, que possuísse significado e valor para os alunos do curso de Administração foi perguntado aos participantes e aos futuros participantes $(n=168)$ quais os principais temas de interesse para a composição do conteúdo de uma futura edição da SIGICar. 
Os resultados, quando somados todos os interesses foram: planejamento profissional; gestão de carreira e mercado de trabalho; gestão empresarial e empreendedorismo; mercado financeiro; liderança e orientação profissional; e curiosidades sobre a área acadêmica e a pós-graduação, nessa ordem. A ciência desses interesses deverão ajudar a compor a elaboração, a distribuição de temas e os convites para professores e profissionais de mercado, para as próximas edições do evento de extensão.

Na análise de construção da carreira do estudante de Administração na UFRRJ foram analisados parâmetros de percepção e de metamodelos de criação de arquétipos (modelos a serem seguidos para o desenvolvimento de carreira), conforme evidenciado anteriormente. Os estudantes possuem alta expectativa em relação à condução de sua carreira (Xavier $e t$ al., 2011), mostrando preocupação em relação ao seu desenvolvimento e gestão (Calvosa, 2020).

Para realizar a desconstrução das características técnicas e comportamentais ligadas às personagens e personalidades admiradas pelos alunos, após a Análise de Conteúdo, em questões abertas e de livre expressão, foram agrupados e emparelhados sinônimos (critério léxico de agrupar sintagmas por analogia) na fase de tratamento dos resultados, inferência e interpretação (Bardin, 2010), para gerar uma comunicação coletiva da amostra sobre tal objeto de observação.

Os principais achados podem ser observadas no Quadro 8, em uma visão simplificada:

Quadro 8. Percepções da Amostra Total (n=168) sobre a sua Construção de Carreira.

\begin{tabular}{|l|c|l|}
\hline \multicolumn{1}{|c|}{ Proposições } & \multicolumn{2}{c|}{ Resultados } \\
\hline \multirow{4}{*}{$\begin{array}{l}\text { Principais características presentes em um administrador } \\
\text { de empresas eficaz: }\end{array}$} & $\mathbf{1}^{\mathbf{a}}$ & Exercer liderança \\
\cline { 2 - 3 } & $\mathbf{2}^{\mathbf{a}}$ & Comunicar-se bem \\
\cline { 2 - 3 } & $\mathbf{3}^{\mathbf{a}}$ & Ser organizado ou eficiente \\
\cline { 2 - 3 } $\begin{array}{l}\text { Competências exigidas para a construção } \\
\text { de carreira bem-sucedida de um }\end{array}$ & $\mathbf{4}^{\mathbf{a}}$ & Ter empatia \\
administrador de empresas: & $\mathbf{1}^{\mathbf{a}}$ & Ter a capacidade de liderar \\
\cline { 2 - 3 } & $\mathbf{2}^{\mathbf{a}}$ & Saber trabalhar em equipe \\
\cline { 2 - 3 } & $\mathbf{3}^{\mathbf{a}}$ & Promover mudanças \\
\cline { 2 - 3 } $\begin{array}{l}\text { Competências relevantes para a construção } \\
\text { de sua própria carreira: }\end{array}$ & $\mathbf{4}^{\mathbf{a}}$ & Aprimorar a comunicação \\
\hline & $\mathbf{1}^{\mathbf{a}}$ & Saber se comunicar \\
\cline { 2 - 3 } & $\mathbf{2}^{\mathbf{a}}$ & Desenvolver liderança \\
\cline { 2 - 3 } & $\mathbf{3}^{\mathbf{a}}$ & Diminuir o nível de ansiedade \\
\cline { 2 - 3 } & $\mathbf{4}^{\mathbf{a}}$ & Ter conhecimento técnico \\
\hline
\end{tabular}

Fonte: Dados da pesquisa.

Sobre a Tabela 8 pode ser notado que exercer e desenvolver liderança e comunicação estão entre as principais competências aspirações de carreira para o estudante de Administração da UFRRJ e do CEDERJ. O que confirma os arquétipos citados por ambas as amostras como metamodelos de exercício de Administração, reconhecidamente, bons comunicadores e líderes empresariais em seus ramos de atuação. Outros fatores citados como promover mudanças e ter conhecimentos específicos mostram os valores e preocupações tradicionais das Gerações $\mathrm{Y}$ e $\mathrm{Z}$ na construção de sua carreira, tendo a amostra um posicionamento relativo que vai ao encontro da literatura específica sobre o tema. Saber trabalhar em equipe é um valor mais característico da Geração Y do que da Geração Z. Ele pode ter aparecido como um valor forte na amostra devido à idade média da amostra ou questões envolvendo o período pandêmico no qual a pesquisa fora realizada. Geralmente, mesmo na Geração Y, ele aparece como um valor mediano, devido ao carácter mais individualista dessa geração laboral. 


\section{Conclusões}

A ação de extensão SIGICar foi proposta como um espaço de diálogo e compartilhamento de experiências entre os diversos atores da UFRRJ e do mercado de trabalho, pautado pela liberdade de expressão, para desenvolver o senso crítico e proporcionar uma formação responsável no aluno de Administração nas modalidades presencial e EaD. Mas, extensível a todos os alunos convidados do Instituto de Ciências Sociais Aplicadas - ICSA / UFRRJ e para a comunidade acadêmica.

A atenção dada à questão de pesquisa do trabalho e ao objetivo norteador da pesquisa envolveram as seguintes conclusões, respectivamente: os formatos e temas a serem oferecidos em um evento de extensão para promover a devida contribuição na formação profissional e pessoal dos alunos parece oscilar de acordo com quatro variáveis: modalidade de ensino presencial ou EaD; idade do estudante, tempo de experiência profissional e proximidade ou não do local do evento para a residência do participante. E esses fatores deverão ser levados em conta em proposta futuras de eventos de extensão, quer seja na UFRRJ ou em outra instituição, pelo menos, que se aproxime da realidade das Ciências Sociais Aplicadas. Outras variáveis não ofereceram significativa oscilação: diferença de gênero, estado civil, ter ou não filhos, diferença de raça (pelos critérios estabelecidos pelo IBGE, conforme questão específica do formulário eletrônico) ou condição socioeconômica. Com base nos achado, para atingir o objetivo do trabalho e melhor responder a própria questão de pesquisa, as conclusões foram divididas em dois grupos com duas macroorientações distintas,: um grupo que já havia participado de uma ou mais edições da SIGICar (logo, com experiência e senso crítico sobre o formato, o conteúdo, a metodologia de ensino-aprendizagem, as ferramentas utilizadas e a proposta da semana acadêmica) - Grupo 1; e um grupo que nunca havia participado de nenhuma edição da SIGICar (logo, com expectativas e ansiedades sobre o evento, em relação à sua construção de carreira) - Grupo 2.

O Grupo 1 - Participantes da SIGICAR - possui como marcadores principais: o ensino presencial; a menor faixa etária comparativa; o menor tempo de experiência profissional; e a menor distância comparativa do local do evento para a residência do participante. Ele possui as seguintes características: é composto de mais jovens, solteiros, sem filhos e estão nos períodos mais iniciais do curso, quando comparado ao outro grupo; não havia participado de nenhuma semana acadêmica antes; possui pouca experiência profissional; a sua orientação e carreira envolve principalmente ter estabilidade, ser realizado profissionalmente e viajar e conhecer pessoas; possui grande ansiedade em relação a seu futuro profissional; aprova o formato, o conteúdo e a programação da semana acadêmica realizada; rejeita a variedade de atividades programadas ofertadas; busca uma postura mais passiva como participante; prefere que futuras edições do evento limite-se ao período vespertino; busca temas que o prepare para entrar no mercado de trabalho ou para a pós-graduação; prefere palestrantes externos ao curso que realiza; acredita que as competências necessárias para um estudante ser um competente profissional envolve exercer liderança, saber se comunicar, diminuir o nível de ansiedade, e para um gestor ser eficaz envolve ter empatia, ter foco e organização, ter conhecimento e bom relacionamento interpessoal; alistou a cantora Anitta como principal como modelo de gestão empresarial e de gestão de carreira e a empresa Apple como a mais admirada. Parece que os seus metamodelos de personalidade empresarial célebre e empresa estão entre os amplamente divulgados na mídia, e possui relação com suas aspirações de consumo, logo, são influenciados por um modelo de gestão mais distante, abstrato.

O Grupo 2 - Futuros Participantes da SIGICAR - possui como marcadores principais: o ensino EaD; a maior faixa etária comparativa; o maior tempo de experiência profissional; e a maior distância comparativa do local do evento para a residência do participante. Ele possui as seguintes características: possui experiência profissional de 12 anos; menor necessidade de movimentações de carreira para atingir o seu objetivo profissional; a sua orientação e carreira envolve principalmente ter estabilidade, ser realizado profissionalmente e conciliar trabalho e família (uma seleção natural, devido a ter maior proporção de casados e pais); gostaria de ter como palestrantes os professores do curso e os profissionais de mercado em proporções similares; indica o desejo de participar em muitas atividades propostas, de forma virtual; busca a variedade de atividades programadas ofertadas; não apresenta rejeição em relação a uma postura ativa como participante; busca maiores 
instruções, capacitações e oportunidades com ofertas de emprego, com interesse baixo em ofertas de estágio; acredita que as competências necessárias para um estudante ser um competente profissional envolve exercer liderança, saber se comunicar, ter conhecimento técnico, e para um gestor ser eficaz envolve ter a capacidade de liderar, saber trabalhar em equipe e promover mudanças; alistou Silvio Santos e Luiza Trajano como principais como modelos de gestão empresarial e de gestão de carreira e as empresas Google e Amazon como as mais admiradas. Parece que os seus metamodelos de personalidade empresarial célebre e empresa estão entre os mais experimentados e discutidos nos ambientes profissionais, e possui relação com modelos de gestão mais próximos da realidade organizacional e de sua interação empresarial, logo, são influenciados por um modelo de gestão mais próximo, projetado em longo prazo.

Os organizadores da SIGICar, para uma futura edição, pretendem revistas os dados e as informações da pesquisa, para ter a oportunidade de oferecer um evento que alcance, que tenha expressividade e representatividade para os alunos e para a comunidade acadêmica. Por isso, tentará se adaptar aos principais pedidos e considerações. Também, organizar um cronograma e um conteúdo programático com indicações específicas de melhor proveito para os participantes, que melhor descreva o tipo de atividade, a proposta metodológica, a possibilidade de interação na atividade, a biografia do facilitador/participante, a sugestão de horário e de classificação das atividades pelos critérios de modalidade de ensino e experiência profissional. Os autores acreditam que esse conjunto de práticas possam ser estendidas para outras experiências de extensão ou para outras instituições. Com isso, calcula-se que as futuras ações de extensão ajudarão na maior retenção, senso de pertencimento e identificação dos estudantes com o curso; direcionamento de ações de pesquisa e extensão; melhoria no rendimento acadêmico dos estudantes e melhor gerenciamento e autogestão da própria da carreira discente.

Os alunos, não raro, direcionam suas expectativas em busca de conselhos, orientações e insights para terceiros, como mentores, profissionais e mercado ou professores, que lhes possam apontar uma direção, mesmo após a formatura. Iniciativas como projetos de extensão, projetos educacionais e tecnologias em educação, quando orientadas e abrigadas dentro de uma metodologia adequada mostram-se, pelo menos no início da sua carreira, necessárias para a composição de carreira do estudante. Os estudantes anseiam por "líderes" e mentores que os ajudem a solidificar um caminho a ser seguido, quando, em um primeiro momento, o caminho parece obscuro e sem as devidas perspectivas.

Futuras pesquisas deverão ser realizadas com novas amostras do curso de Administração. Se em ambiente de ensino público, para buscar um viés confirmatório ou contraditório sobre a atual pesquisa. Outra oportunidade será comparar os resultados da realidade de um curso público de graduação com um curso particular. Novas pesquisas poderão ser realizadas, ainda, com outros cursos de graduação. Ou, direcionadas, para a essencialidade da extensão universitária diante da atual e urgente discussão sobre a percepção dos alunos sobre a curricularização da extensão. Como "amarga' experiência dos organizadores nas três edições oferecidas da SIGICar, os número mostram que cerca de 5\% dos estudantes tiveram alguma participação no evento (pelo menos uma efetivação entre as cerca de 20 a 25 ofertas de atividades) e cerca de $2 \%$ participaram da pesquisa, entre todos os convidados. Como discussão, entendemos que o tema extensão pode e de ser melhor pesquisado, investigado, oferecido e divulgado na esfera da pesquisa científica e no próprio exercício da extensão universitária. Por isso, como autores, nos colocamos à disposição para apoiar novas iniciativas de pesquisa, como as supracitadas, por exemplo.

\section{Agradecimentos}

Ao Grupo de Pesquisas Gestão de Carreiras e Planejamento Estratégico Pessoal - GeCaPEP (dgp.cnpq.br/dgp/espelhogrupo/7765312712894655) por toda a colaboração e envolvimento na pesquisa científica, assim como, pelo apoio e suporte metodológico. O GeCaPEP estimula e orienta acadêmicos e pesquisadores de forma gratuita e voluntária pelo Instagran: @ pesquisas.gecapep. 


\section{Referências}

Abdalla, M., Calvosa, M, \& Batista, L. (2013). Hélice Tríplice no Brasil e na América Latina: fomentando o desenvolvimento através do ator universidade. Revista Iberoamericana de Educación, 61(1), 1-12.

Bardin, L. (2010). Análise de Conteúdo. (4a ed.), Edições 70.

Calvosa, M., \& Ferreira, M. (2021). Os Atuais Pesquisadores sobre o Tema Liderança estão presos ao Modelo Mental do Século XX? In: XLV Enanpad Encontro da Anpad, Curitiba.

Calvosa, M. (2021). Liderança Empresarial e Estratégica. Fundação Cecierj.

Calvosa, M.; Carvalho, C.; Lima, M. de; Januário, E. (2020). Liderança e as Mídias Sociais Virtuais. In: XXIII Semead - Seminários em Administração FEA USP, São Paulo.

Calvosa, M. (2020). Perspectivas e Decisões de Carreira: dilemas entre a vida profissional e pessoal. Revista de Casos e Consultoria, 11(1), e11129. https://www.researchgate.net/publication/354810841

Calvosa, M. (2008). As Competências e as Expectativas do Futuro Administrador: o estudo do perfil do estudante de Administração da UFRRJ. Revista Universidade Rural. Serie Ciências Humanas, 29, 201-218.

Coradini, N., Borges, A., \& Dutra, C. (2020). Tecnologia educacional Podcast na Educação Profissional e Tecnológica. Revista Eletrônica Científica Ensino Interdisciplinar, 6(16).

Castro Júnior, D, Deluca, M., Barp, A., De Souza, I., \& Abreu, J. de (2019). Competências Gerenciais: estudo de caso das funções da coordenação de curso superior em Administração. Revista Eletrônica Científica do CRA-PR, 6(2), 16-29.

Gatti, B. (2021). Formação de Professores no Brasil: políticas e programas. Paradigma, 42(2), 1-17.

Greff do Amaral, J. F., Rocha, A. F. R., Santos da Rosa, B. A., \& da Fonseca Patias, L. (2020). Os Impactos do Fracionamento de Investimentos em Bolsas de Pesquisa no Ensino Púbico. Revista Missioneira, 22(1), 76-84.

Gouveia, L., Abdalla, M., \& Calvosa, M. (2009). Hélice tríplice no Brasil: A entrada da universidade nas parcerias público-privadas. In: XII Semead Seminários de Administração, São Paulo.

Johnson, N., Turnbull, B., Reisslein, M. (2022). Social media influence, trust, and conflict: An interview based study of leadership perceptions. Technology in Society, 68, 101836

Leite, R., Krakauer, P., \& Calvosa, M. (2020). Mentorias Spot: Oportunidade de Orientação Profissional para Iniciativas Empreendedoras. In: XI EGEPE Encontro de Estudos sobre Empreendedorismo e Gestão de Pequenas Empresas, Belo Horizonte / MG.

Luo, G. (2020). A Study on the Value of New Generation Employee Help Scheme in Industrial Organization. Advances in Social Science, Education and Humanities Research, 451, 335-341.

Mello, K., Aparício, I., Oliveira, P., \& Calvosa, M. (2009). Desenvolvimento de carreira: o papel da mulher nas organizações. Revista Cadernos de Administração, 2, 130-148, https://www.researchgate.net/publication/357098066

Minayo, M. C. (2002). Pesquisa Social: teoria, método e criatividade. (21a ed.), Editora Vozes.

Ministério da Educação e Cultura - MEC. (2022a). Educação Profissional e Tecnológica (EPT). Secretaria de Educação Profissional e Tecnológica. http://portal.mec.gov.br/educacao-profissional-e-tecnologica-ept

Ministério da Educação e Cultura - MEC. (2022b). Conselho Nacional de Educação. Câmara de Educação Superior. Resolução No 7 , de 18.dez.2018. http://portal.mec.gov.br/index.php?option=com_docman\&view=download\&alias=104251-rces007-18\&category_slug=dezembro-2018-pdf\&Itemid=30192

Mozzato, A., \& Grzybovski, D. (2011). Análise de Conteúdo como Técnica de Análise de Dados Qualitativos no Campo da Administração: potencial e desafios. Revista de Administração Contemporânea, 15 (4), 731-741.

Ötting, S. K., Masjutin, L. \& Maier, G. W. (2021). The future of leadership - How is leadership in small and medium-sized enterprises going to change? Journal Gruppe. Interaktion. Organização - GIO, 52, 639-647.

Partnership for 21st Century Learning - P21. (2019). A Network of Battelle for Kids, Framework for 21st century learning definitions. http://static.battelleforkids.org/documents/p21/P21_Framework_DefinitionsBFK.pdf.

Putriastuti, B., \& Stasi, A. (2019). How to lead the millennials: a review of 5 major leadership theory groups. Journal of Leadership in Organizations, $1(2), 96-111$.

Santana, R. de. (2020). A Tecnologia Educacional e a Educação a Distância no Século XXI. Revista Scientia, Salvador, 5(3), 77-101.

Santos, S. de. (2019). O Uso das Tecnologias na Formação Profissional e Tecnológica: um estudo de caso do Centro Territorial de Educação Profissional do Extremo Sul (Cetepes). Revista IFES Ciência, 5(2), 175-186.

Seufert S., Guggemos J., \& Sailer, M. (2021). Technology-related knowledge, skills, and attitudes of pre- and in-service teachers: The current situation and emerging trends, Computers in Human Behavior, 115(106552), 1-9. 
Research, Society and Development, v. 11, n. 2, e58411225991, 2022

(CC BY 4.0) | ISSN 2525-3409 | DOI: http://dx.doi.org/10.33448/rsd-v11i2.25991

Silliman, B., Edwards, H., \& Johnson, J. (2020). Long-term Effects of Youth Work Internship: The Project Youth Extension Service Approach, Journal Preproof, 119(105436), Sept.

Souza Neto, S., \& Calvosa, M. (2006). As Competências de Liderança: Atributos e Práticas do Líder do Século XXI, uma Pesquisa Quantitativa. Revista de Administração da Unimep 4(1),68-94. https://www.researchgate.net/publication/283900737

Teixeira, M. A, Dias, A. C. G., Wottrich, S. H., \& Oliveira, A. M. (2008). Adaptação à universidade em jovens calouros. Psicologia Escolar e Educacional (Impr.), Campinas, 12(1),185-202.

Xavier, A., Lopes, P., Vilhena, T., \& Calvosa, M. (2012). Desenvolvimento Pessoal e Profissional de Futuros Gestores: como a Geração Y encara as competências necessárias para o aumento da empregabilidade e para o sucesso no ambiente profissional. In: XXXVI Enanpad - Encontro da Anpad, Rio de Janeiro.

Xavier, A., Espirito Santo, R. V., \& Calvosa, M. (2011). O Perfil do Estudante de Administração de Ensino Superior: um estudo comparativo entre amostras de uma universidade federal do Rio de Janeiro. In: XIV Semead - Seminários em Administração da USP, São Paulo. 